
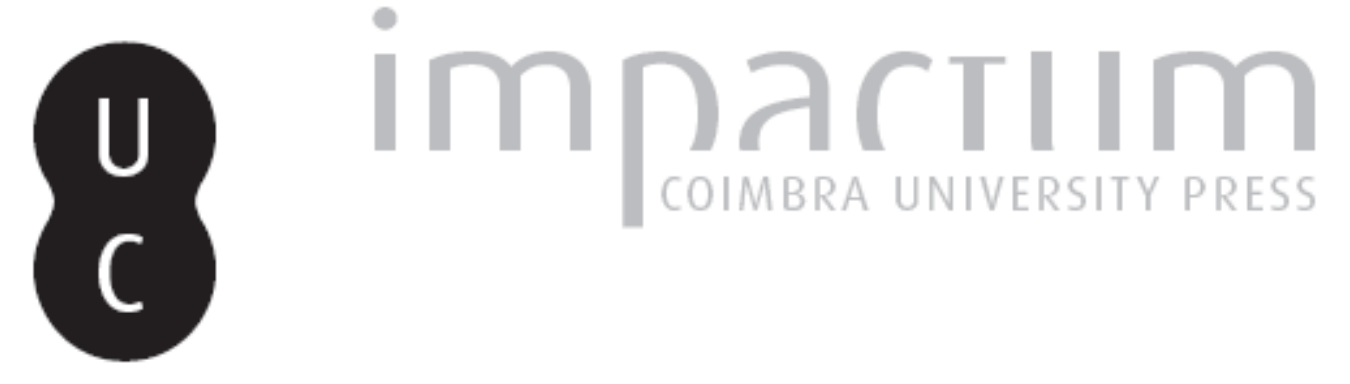

\title{
A epígrafe latina como elemento didáctico (XXIII)
}

\author{
Autor(es): $\quad$ Encarnação, José d'
}
Publicado por: Associação Portuguesa de Estudos Clássicos; Instituto de Estudos Clássicos

URL persistente:

URI:http://hdl.handle.net/10316.2/30473

DOI:

DOI:http://dx.doi.org/10.14195/0872-2110_49_10

Accessed : $\quad$ 26-Apr-2023 12:17:17

A navegação consulta e descarregamento dos títulos inseridos nas Bibliotecas Digitais UC Digitalis, UC Pombalina e UC Impactum, pressupõem a aceitação plena e sem reservas dos Termos e Condições de Uso destas Bibliotecas Digitais, disponíveis em https://digitalis.uc.pt/pt-pt/termos.

Conforme exposto nos referidos Termos e Condições de Uso, o descarregamento de títulos de acesso restrito requer uma licença válida de autorização devendo o utilizador aceder ao(s) documento(s) a partir de um endereço de IP da instituição detentora da supramencionada licença.

Ao utilizador é apenas permitido o descarregamento para uso pessoal, pelo que o emprego do(s) título(s) descarregado(s) para outro fim, designadamente comercial, carece de autorização do respetivo autor ou editor da obra.

Na medida em que todas as obras da UC Digitalis se encontram protegidas pelo Código do Direito de Autor e Direitos Conexos e demais legislação aplicável, toda a cópia, parcial ou total, deste documento, nos casos em que é legalmente admitida, deverá conter ou fazer-se acompanhar por este aviso.

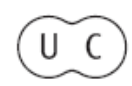




\section{Boletim de}

\section{Estudos Clássicos}

Associação Portuguesa de Estudos Clássicos Instituto de Estudos Clássicos

Coimbra

Junho de 2008 


\title{
A EpíGRAFe Latina COMO ElEMENTO DiDÁCTICO (XXIII)
}

\author{
Os cavaleiros
}

Como se sabe, a pertença a uma «classe», na época romana, estava determinada pelo censo, ou seja, pelo rendimento anual atribuível à pessoa. Assim, para se ser cavaleiro, necessitava-se de não usufruir menos de 400000 sestércios.

Dir-se-á, desde já, que não se pode considerar a 'classe' dos cavaleiros como se se tratasse de uma espécie de «classe média» entre os senadores e o povo. Aliás, essa foi uma questão controversa que surgiu a partir da obra de H. Hill, The Roman middle class in the republican period, Oxford, 1952. Vários comentadores se insurgiram contra essa designação, entre os quais G. Vitucci, que, em recensão àquele livro $^{1}$, mostra como pode incorrer-se numa interpretação deficiente - porque de interpretação económica, actual - do que foi a realidade romana, designadamente na época dos Gracos. Para existir uma 'classe', sublinha, é preciso haver consciência disso e, em Roma, tal só acontece no momento em que «os cavaleiros, que inicialmente se distinguiam sobretudo por possuírem mais bens dos que as classes inferiores, começaram a firmar os seus interesses em contraste com aqueles que, embora fizessem parte da classe do governo da oligarquia senatorial, ocupavam, apesar de tudo, o mesmo escalão dentro da ordenação timocrática do Estado».

Hill responderia a estas críticas $^{2}$, reafirmando que a expressão não detinha conteúdo equiparável ao da «classe média» da actualidade, mas visava apenas assinalar que os cavaleiros estavam, de facto, entre os senadores e a plebe.

Reconheça-se que, mesmo em termos arqueológicos - se assim nos podemos exprimir - nas cerimónias ou nos espectáculos públicos, senadores e cavaleiros ocupavam lugar de destaque e a plebe se sentava em lugares inferiores, bem distintos...

${ }^{1}$ In Rivista di Filologia e di Istruzione Classica, Turim, 32, 1954, p. 82-85.

2 «The Equites as a "Middle Class"», Athenaeum, 33, 1955, p. 327-332. 
A «classificação» como cavaleiro não era hereditária e só os filhos de senadores nasciam, «oficialmente», cavaleiros; na prática, porém, os filhos de cavaleiros pertenciam à classe do pai e, desta sorte, quando se diz de alguém que é 'cavaleiro de origem' é porque nos estamos a referir ao filho de um cavaleiro.

Já tivemos ocasião de mostrar como a sociedade romana se caracterizava por uma grande permeabilidade. Quer dizer: pode nascer-se cavaleiro; mas também se pode ascender a essa categoria, ou porque, entretanto, se alcançou o censo mínimo necessário para o efeito - e, nesse caso, os censores teriam de o inscrever na lista oficial dos cavaleiros - ou por se ter atingido alguma notoriedade social ou económica.

Aos cavaleiros estavam reservadas funções administrativas e funções militares, sem que o facto de ser cavaleiro implique a necessidade de ter cavalo ou de combater a cavalo. Estamos a falar mais de um status do que de uma função.

Assim, os soldados que se notabilizavam poderiam ascender à 'ordem' da cavalaria e os notáveis municipais também. A forma de acesso de uns e de outros tem constituído - e constituiu sobretudo nos meados do século passado - assunto de alguma polémica. Uma polémica, de resto, compreensível, porque os únicos elementos de que dispomos com alguma fiabilidade para tentar desenrolar o fio à meada são precisamente as inscrições em que consta o cursus honorum equestre. Ora, como facilmente se compreende, quem ascende a cavaleiro não vai ter muito interesse em que, numa inscrição em sua honra, se explicitem as funções que ocupou antes; o que lhe interessa é o que vai fazer depois, o que fez depois.

E a polémica centrou-se, de modo especial, no conteúdo e categoria de dois cargos: para os militares, o primipilatus; para os notáveis municipais, a praefectura fabrum. São ambas já escalões da carreira equestre, os primeiros, ou, apenas, a função de transição, sem pertencerem a nenhuma das categorias? $?^{3}$

O primipilus é o centurião que comandava a primeira centúria da primeira coorte numa legião; o praefectus fabrum, à letra, «prefeito dos

${ }^{3}$ S. J. de Laet - um dos autores que, na década de 40 do século passado, mais se debruçou sobre as questões que se prendem com o estatuto social do cavaleiro demonstra que, no dealbar do Império, o primipilus pertence, de facto, à classe equestre: cf. «Le rang social du primipile à l'époque d'Auguste et de Tibère», L'Antiquité Classique (Lovaina), IX, 1940, p. 13-23. 
artífices», era como que o ajudante-de-campo de um 'oficial'. Compreendese: o primipilus detinha uma acção preponderante na táctica de combate e isso o introduzia nos complexos meandros das estratégias militares; por isso, estava a um passo de ser nomeado cavaleiro; o praefectus fabrum, por seu turno, era pouco a pouco iniciado nas malhas da burocracia e da administração e, por consequência, passado esse estágio, era facilmente guindado a assumir responsabilidades maiores a nível dos mecanismos decisórios. Como escreveu o já citado S. J. de Laet, «pela sua composição, a ordem equestre constituía já, sob os primeiros imperadores, uma amálgama de escol municipal, provincial e intelectual do Império. Mais do que a ordem senatorial, a ordem equestre era a imagem das forças vivas da nação» (ibidem, p. 21-22). Aliás, tudo isso fazia parte - e S. J. de Laet sublinha-o de uma estratégia política bem definida por parte do imperador Augusto:

«Ao elevar o primipilado ao grau de função equestre, Augusto demonstrou que desejava ver o escol militar e municipal subir às classes sociais superiores, para aí levar sangue novo e transformar pouco a pouco a nobreza romana em nobreza do Império».

Ser cavaleiro era, pois, um orgulho e, por isso, não raro surgem nas inscrições - mormente dos cavaleiros de fresca data - os títulos que denunciavam essa categoria:

- eques romanus equo publico: título atribuído, pelo imperador, aquando do recenseamento; dava lugar às já referidas honras visíveis, como a ocupação de lugares no teatro logo a seguir aos senadores;

- splendidus eques romanus: o adjectivo realça a importância social;

- um funcionário imperial, cavaleiro, pode vir, nas epígrafes, identificado como $\mathrm{V}($ ir $) \mathrm{E}$ (gregius); um prefeito será $\mathrm{V}$ (ir) $\mathrm{P}($ erfectissimus); o prefeito do pretório - e só ele - V(ir) EM(inentissimus).

Se alguém se identifica como honoratus equo publico isso significa que foi agraciado com o cavalo público, isto é, que ingressou na ordem equestre por favor imperial: trata-se, portanto, de um homo novus.

Poderemos interrogar-nos por que razão não se encontraram, até ao momento, no território actualmente português, significativas epígrafes em honra de cavaleiros.

A primeira razão já foi aduzida em relação a outros tipos de monumentos de carácter eminentemente urbano: os cipos ou os pedestais que os honravam facilmente se reaproveitaram na construção de edifícios, a partir do momento em que se desconheceu o seu valor ou, ainda, por se considerar - Cristianismo implantado - que eram escritos do tempo dos... «pagãos»! 
Há, porém, um outro motivo: é que as funções dos cavaleiros não se exerciam predominantemente na província mas sim noutras zonas do Império. Por conseguinte, não é de admirar que, das poucas referências a cavaleiros na epigrafia romana do nosso território, algumas se prendam com ex-votos. Assim (fig. 1), temos no Museu de Évora a parte inferior de um altar votivo em que um certo Severus se identifica como eques romanus ${ }^{4}$, e o mesmo acontece numa dedicatória à divindade indígena Endovellicus, em que Sextus Cocceius Craterus Honorinus faz questão em como tal se apresentar (IRCP 492). Escreve Nicolet ${ }^{5}$ que assim usavam este título, «com uma espécie de simplicidade afectada, sobretudo quando nada de mais reluzente tinham que mencionar no seu curriculum». Neste caso, porém, também se há-de ter em conta que, perante a divindade, seria de mau gosto ostentar títulos excessivos...

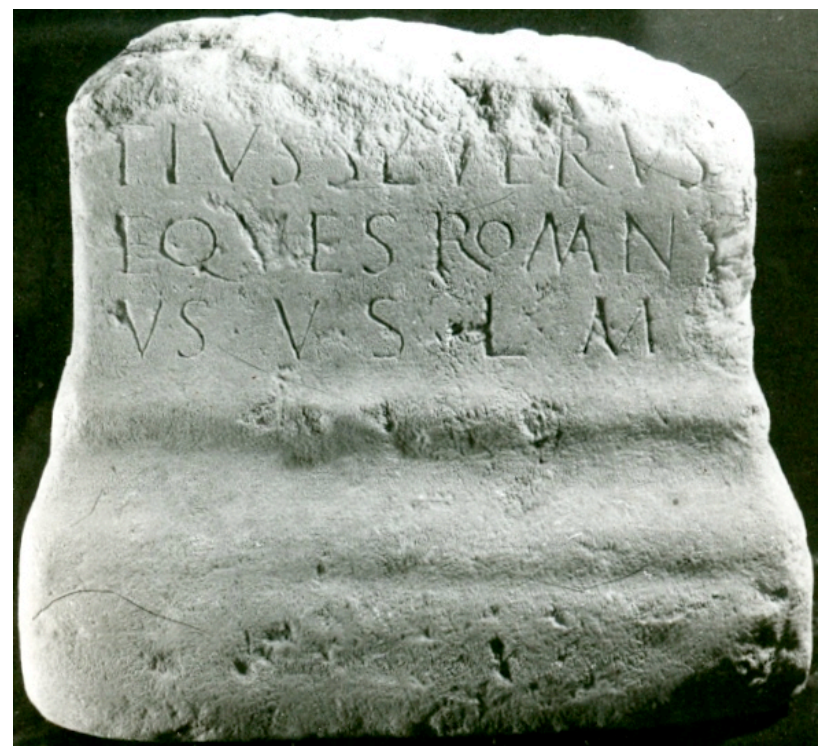

Fig. 1

${ }^{4}$ Cf. José d'Encarnação, Inscrições Romanas do Conventus Pacensis (= IRCP). Coimbra, 1984, inscrição n 376.

5 Claude Nicolet, «La titulature des chevaliers romains», Hommages à Marcel Renard, II, Bruxelas, 1969, p. 565. 
Partindo do princípio de que o notável municipal, elevado à categoria de praefectus fabrum, ganhava com isso novo estatuto e poderia aspirar a outros voos - passíveis de redundar em benefício da comunidade que o vira crescer - não é raro encontrarem-se, ao invés, inscrições em honra de alguém que, depois de haver exercido cargos municipais, é nomeado prefeito dos artífices.

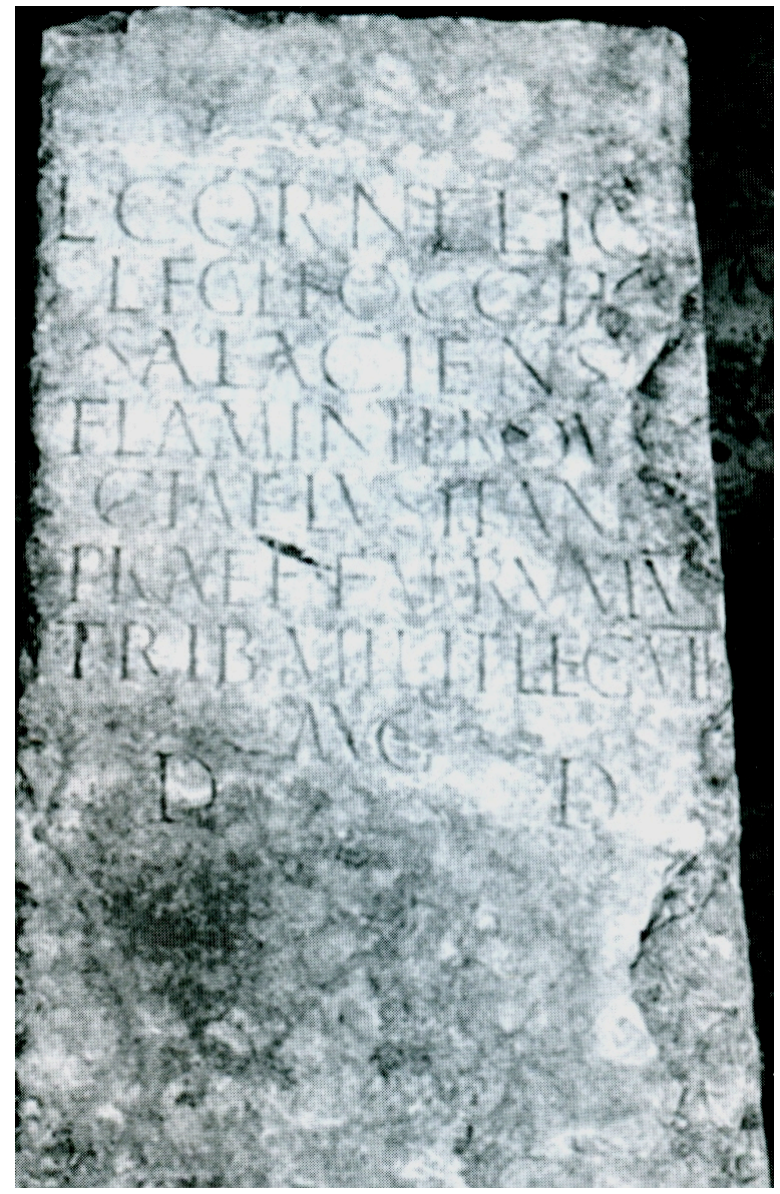

Fig. 2 
Sirva-nos de exemplo a inscrição ${ }^{6}$ exumada das chamadas termas dos Cássios, em Lisboa, referente a um dos personagens mais controversos da Lusitânia, o salaciense Lúcio Cornélio Boco, controverso porque os seus laços familiares, a sua verdadeira identificação não estão suficientemente explícitos, atendendo aos vários monumentos que se lhe referem e nem sempre de forma que se consigam relacionar com clareza...

Não vamos ler toda a epígrafe (fig. 2); apenas referir que, na linha 6, se alude a uma circunstância deveras excepcional: o personagem exerceu a prefeitura dos artífices por cinco vezes (!), antes de ascender ao cargo de tribuno militar da VII Legião Augusta. Uma notável carreira municipal que desembocou brilhantemente em funções de ordem militar.

JOSÉ D'ENCARNAÇÃO

6 Vide A. M. Dias Diogo e Laura Trindade, «Homenagem a L. Cornelius Bocchus, encontrada nas Termas dos Cássios (Lisboa)», Ficheiro Epigráfico, 60, 1999, inscrição $n^{\circ}$ 271. Reproduzimos, com a devida vénia, a fotografia aí publicada e que é da autoria dos signatários do texto. 